\title{
Scanning electron microscopy of intestinal villous structures and their putative relation to digestion and absorption in chickens.
}

\author{
S. H. M. ESMAIL
}

Department of Animal Science, Weber Hall, Kansas State University, Manhattan, KS. 66506, U.S.A.

Summary. Scanning Electron Microscope (SEM) was used to examine villous structures at different parts in the small intestines of 22-week-old chickens. Duodenum revealed plate-like villi with large number of goblet cells on the duodenal epithelium. Jejunum and ileum both revealed leaf-like villi, but the amount of goblet cells was greater in the jejunum. A putative effect of villous structures on the intestinal digestion and absorption is discussed.

\section{Introduction.}

Studying the nature of villi in different parts of the small intestine is important to comprehend the digestion-absorption process in animals (Moran, 1982). Previous work on intestinal villous structures has shown variations from finger-like in pigs (Waxter, 1972) to plate-like in mice (Rao and William, 1972) and young chickens (Bayer et al., 1975), and to totally flat mucosa occurring during disease (Creamer, 1973). Several villous forms were also reported in different segments of small intestines even within the same species (Bayer et al., 1975).

The present study was conducted to determine whether villous structures reported by Bayer et al. (1975) in different parts of the small intestine of young chickens would be the same at an older age, or it seemed possible that other structures might occur as the chickens matured. A putative relation between villous structures and intestinal digestion and absorption is discussed.

\section{Materials and methods.}

Chickens and diets. - Six 22-weeks-old white Leghorn female chickens were selected randomly from a healthy flock fed diets containing $30 \%$ ground yellow corn, $35 \%$ grain sorghum, $5 \%$ oats, $7.5 \%$ alfalfa meal ( $17 \%$ protein), $20 \%$ 
soybean oil meal (44\% protein), $1 \%$ dicalcium phosphate, $1 \%$ calcium carbonate, and $0.5 \%$ salt. Feed additives included trace mineral mixture, Vitamin $A$ and $\mathrm{D}_{3}$, vitamin $\mathrm{B}$ complex, antibiotic supplement, and coccidiostat. These were prepared in a premix containing corn meal as a carrier, and were included at $2 \mathrm{~kg}$ per ton of feed.

Pathological procedures. - All chickens were killed at 22-weeks of age. Samples (about $1 \mathrm{~cm}$ each) were taken from the mid points between ventriculus and cystic duct, cystic duct and yolk stalk, and between yolk stalk and the caeca to represent the duodenum, jejunum, and the ileum, respectively.

Specimens were cut longitudinally, rinsed with saline solution ( 7.5 grams of Sodium Chloride in $1000 \mathrm{ml}$ distilled water), and were fixed in Buffer Neutral Formaline (BNF) for 24 hours. Specimens were then washed briefly in running water for 30 minutes and were dehydrated through graded ethanol series (1 hour each in 50, 70, 80, 95 and $100 \%$ ). Dehydrated specimens were dried in a carbon dioxide critical point drier to avoid exposure of the specimens to any surface tension forces when drying. The dried specimens were mounted on aluminum stubs and double coated in a vacuum evaporator using carbon and gold/palladium. That was done to reduce the build-up of electrons on the specimens, and to make them mechanically stable and conductive to electricity.

Finally, the specimens were viewed and photographed with an ETEC autoscan scanning electron microscope (SEM) at $5 \mathrm{~K} . \mathrm{V}$. accelerating voltage.

Quantitation of the intestinal structures. - Quantitation of the small intestines was done on their major structures. Thus, the ratio of villi to crypts in each intestinal region was obtained at $\times 100$ magnification by measuring both villi areas and crypt areas on each monograph and taking the average of the six measurements. Measurements also involved villous height and crypts depth obtained from light microscopy, using cross sections from the same specimens. At $\times 2000$ magnification, the number of goblet cells in each intestinal region was obtained by simple visual calculations, utilizing the average of six observations for each of the three intestinal regions. From this, the number of goblet cells per unit area of intestine was measured, taking into account the different villous size and density in each intestinal region.

\section{Results.}

SEM examination of the duodenum at $\times 100$ magnification revealed plate-like villi (figure $1-A$ ). These were mostly flat and wide allowing only small areas of mucosal crypts. The ratio of villi to crypts in the duodenum was calculated to be about 10:1. At higher magnification ( $\times 2000$ ), goblet cells were observed to form a significant portion of the villous epithelium (30 cells per unit area), as shown in figure $1-B$. Size of the apical pole of goblet cells varied from 1 to $2 \mathrm{um}$.

The jejunum revealed leaf-like villi at $\times 100$ magnification (figure $2-A$ ). Projection of these villi towards the luminal surface was less extensive than that in the duodenum, i.e. the villi to crypts ratio in the jejunum was only $1.5: 1$. At the higher magnification ( $\times 2$ 000), goblet cell pores in the jejunal villi (figure $2-B$ ) 


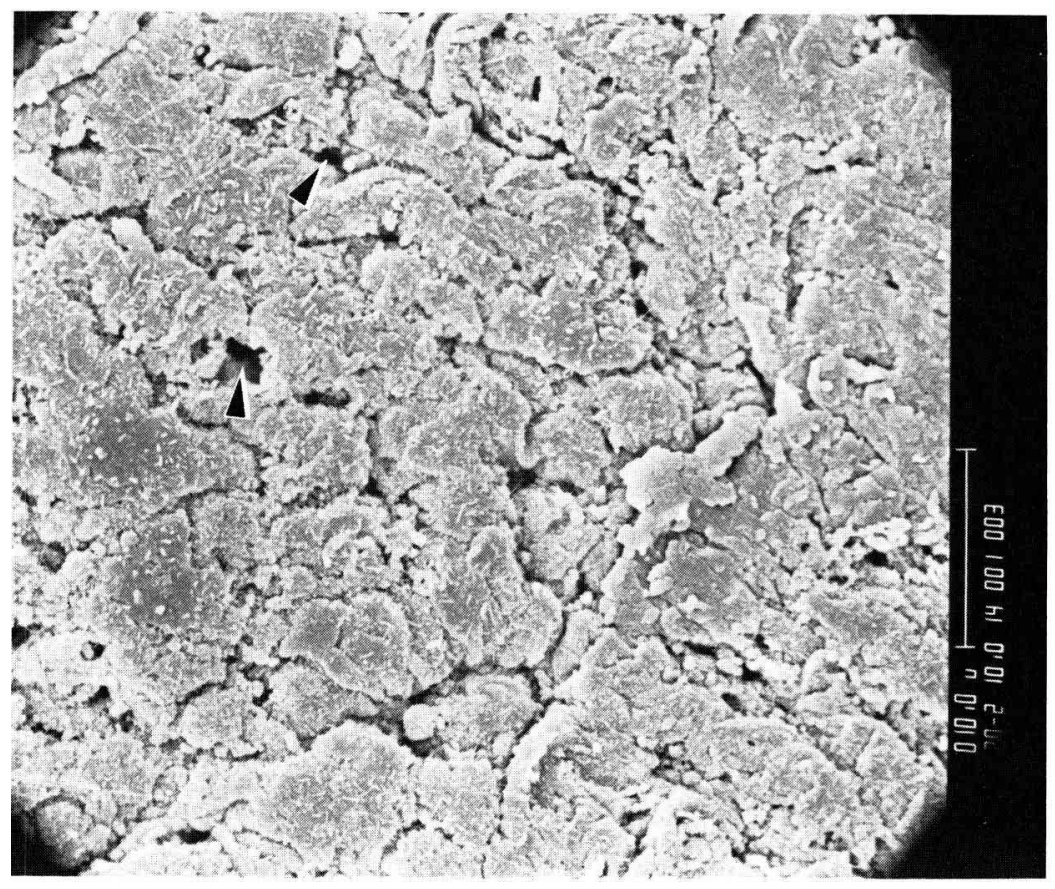

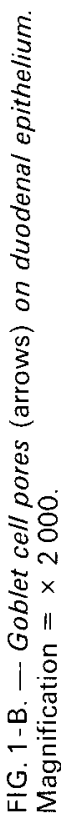

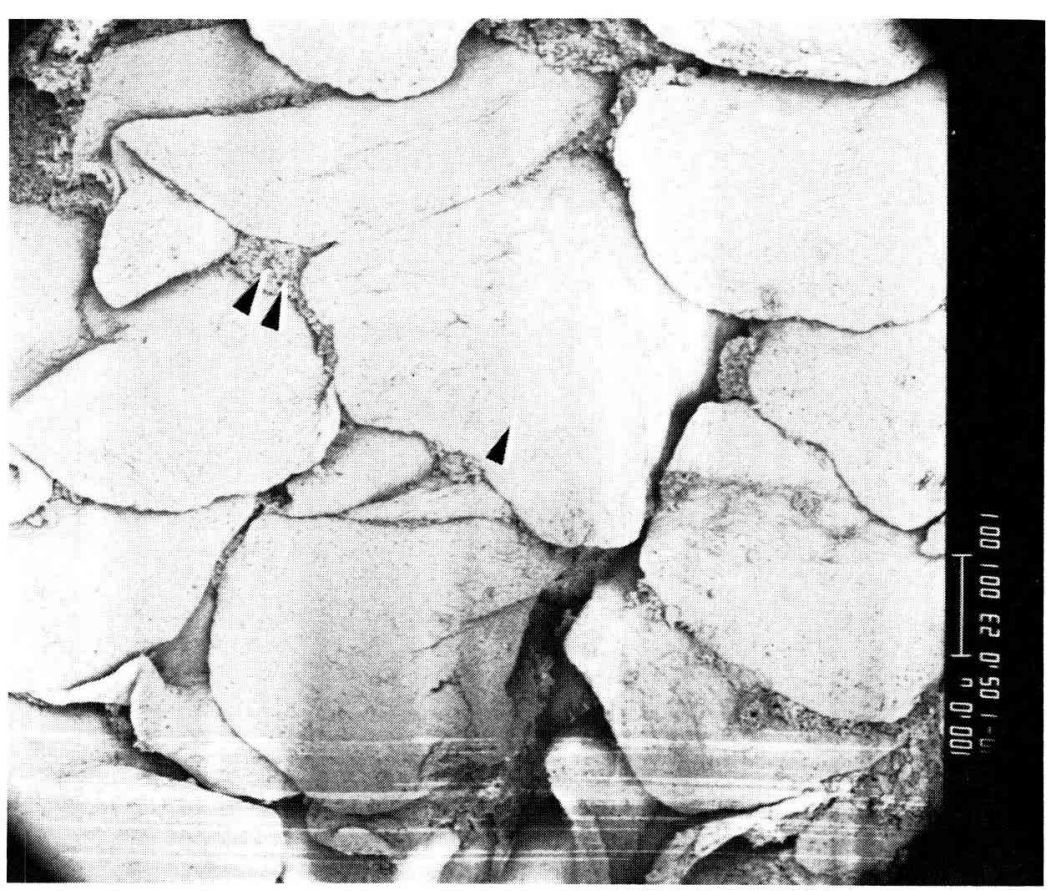

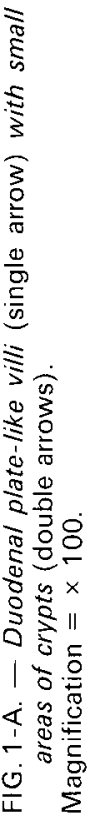




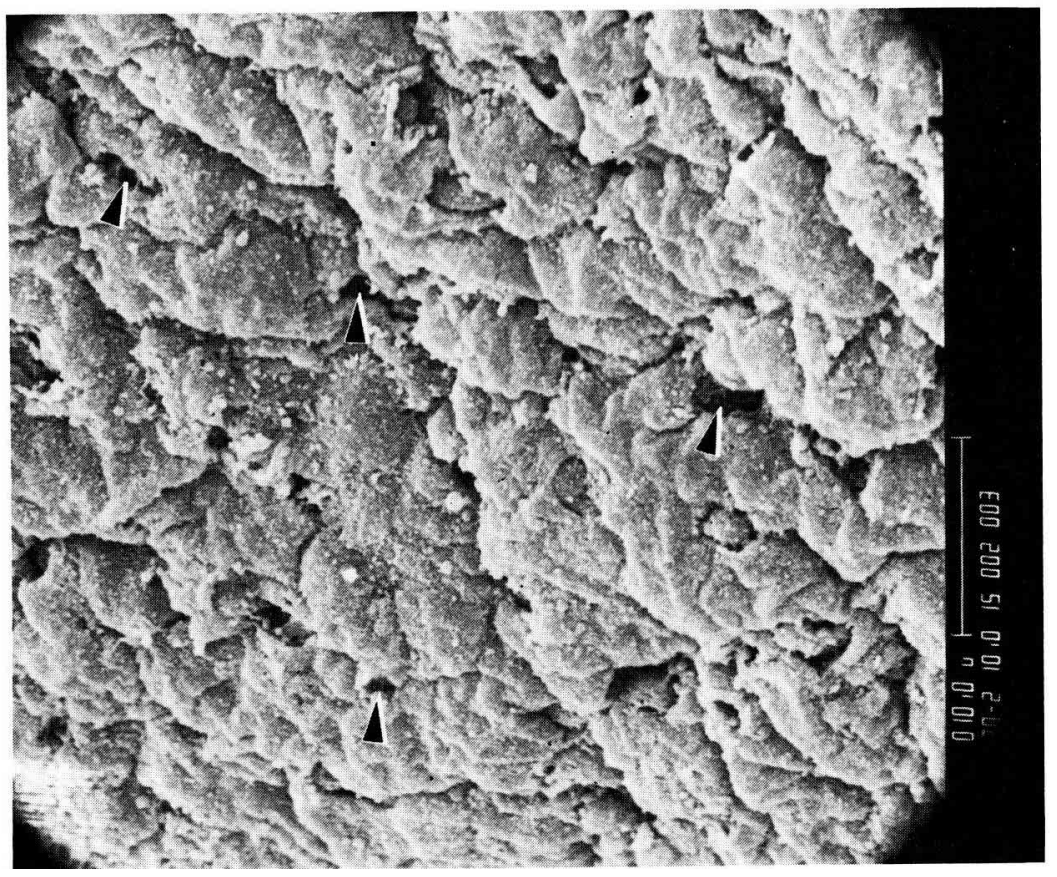

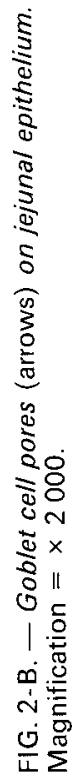

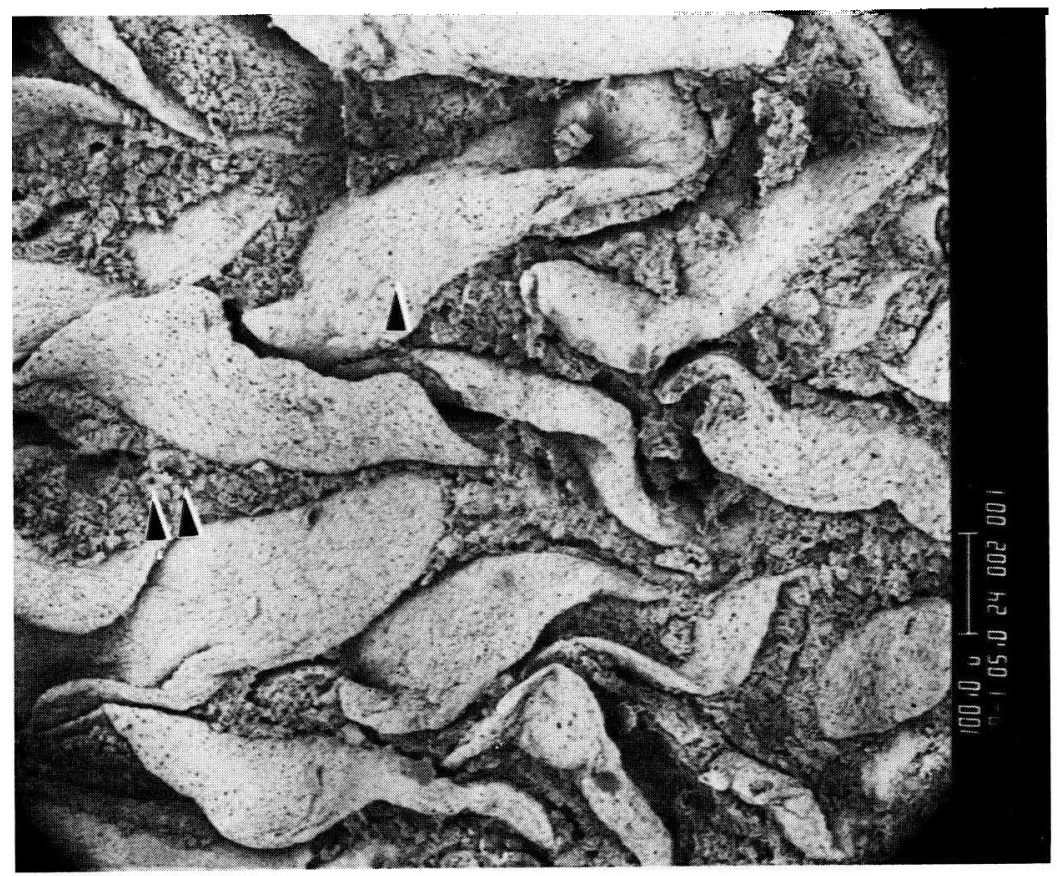

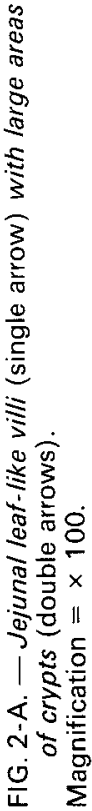


were similar to those observed in the duodenum ( 28 cells per unit area). However, considering the ratio of villi to crypts in duodenum and jejunum, the number of goblet cells per unit area of intestine was greater in the duodenum.

Examination of the ileal villi at $\times 100$ magnification also revealed leaf-like structures (figure 3-A), but these were more narrow than those in the jejunum. Villi in the ileum were more extensively projecting towards the luminal surface as compared to those in the jejunum, but were less extensive than those in the duodenum, i.e. a ratio of $3.5: 1$ was calculated for villi to crypts in the ileum. The ileal goblet cells per unit area of villi were fewer than those in the duodenum and jejunum (only 16 cells per unit area). Size of the apical pole of goblet cells was, however, similar in all the three intestinal segments.

Comparing calculations of ratios of villi to mucosal crypts in duodenum, jejunum, and ileum, and the relative amounts of goblet cells forming the villous epithelium of these regions, it appears that the ileum had the smallest number of goblet cells per unit area of intestines; i.e. a ratio of about $6: 2: 1$ was estimated for the amount of duodenal : jejunal : ileal goblet cells per unit of intestines.

\section{Discussion.}

The intestinal villous structures observed in the present study on 22-weeks-old chickens were in accordance with those observed by Bayer et al. (1975) on young chickens from 1 day through 14 weeks of age. There were minor differences in the size of goblet cells and in the shape of the villi, particularly at the jejunum and the ileum, but these could be due to the effect of age, diet, sex, health, or methodology.

Although the duodenum has been shown to be well equipped with villi, this area largely serves as a mixing and neutralizing site (Moran, 1982), and the partial digestion occurring in this region is considered to be an extension of gastric digestion rather than intestinal digestion. Villi exert their mixing function through different patterns of villous motility. These were described in different species by Green and Greene (1984), as pumping movement, pendular movement, and tonic contractions. No indication, however, was given as to which of these patterns occurs in chickens. Conceivably, the power of villous motility is proportional to the number of villi per unit area. The large amount of villi in the duodenum may allow a greater supply of fibers from the ganglionated nerve plexus of the submucosa to the villi smooth muscle and, hence, allowing sufficient nerve stimulation of villous motility at this site. It is also possible that the abundance of villi in the duodenum allows greater surface area exposed to the gastric acid $\mathrm{HCl}$. This would stimulate release of larger amounts of the mucosal hormone villikinin, which acts on villous motility. These two mechanisms (nervous and hormonal) may provide a clue for the unique mixing function performed at the duodenum.

Having goblet cells concentrated in the duodenum serves to buffer highly acidic digesta from the stomach through the action of goblet mucin, in addition to bile and pancreatic juices. The nature of mucin has been described by Forstner and Forstner (1986), as a wide spectrum of chemicals of alkaline nature secreted 


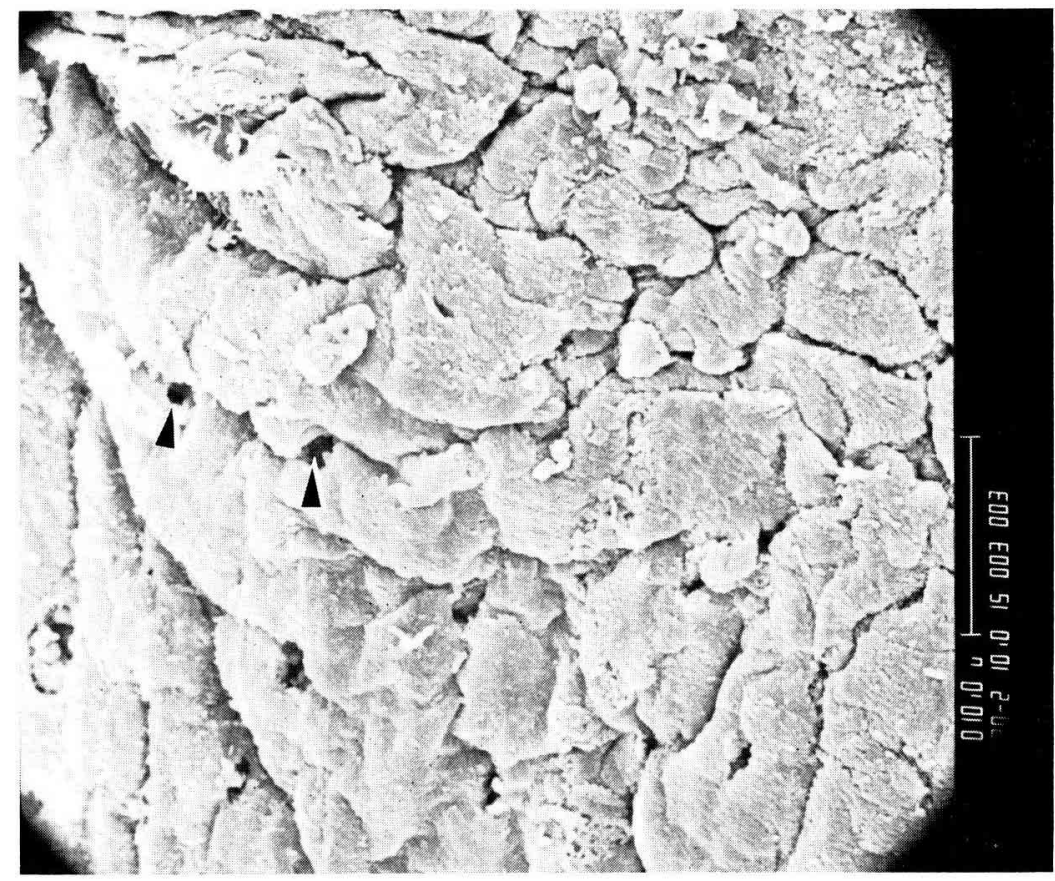

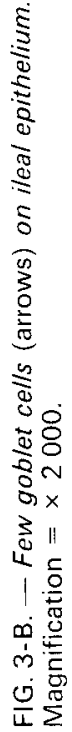

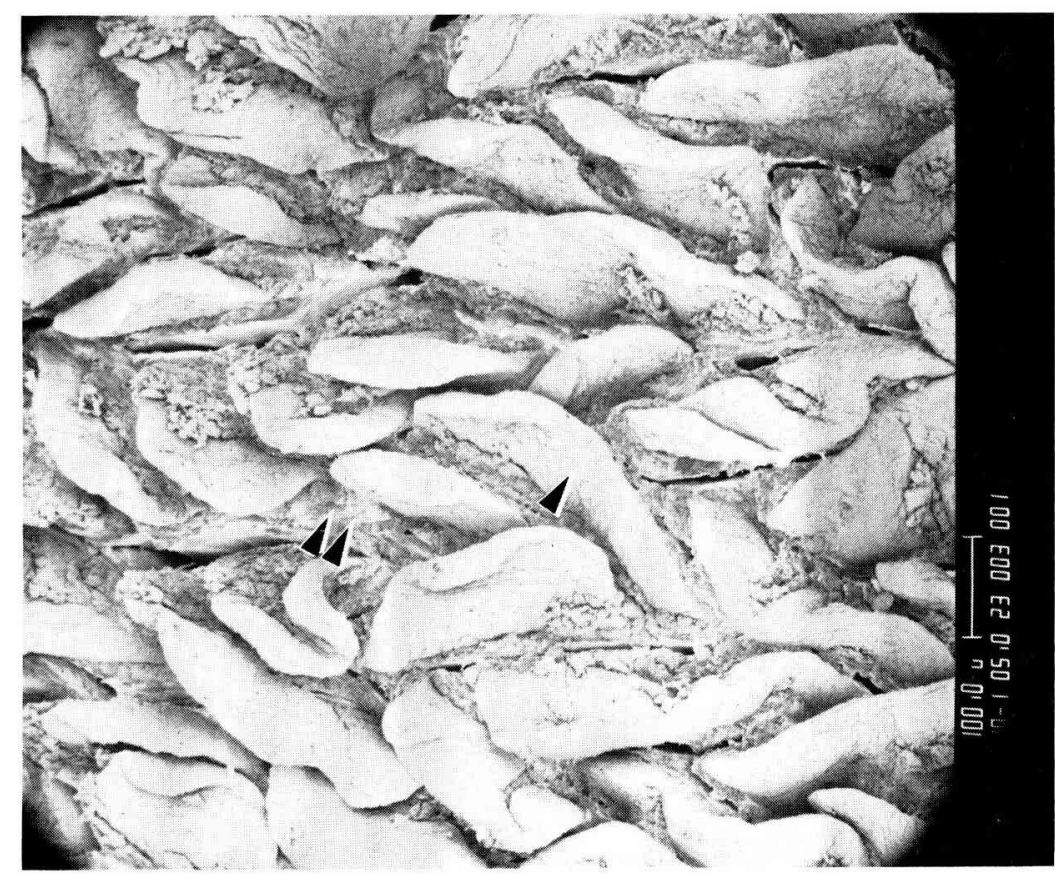

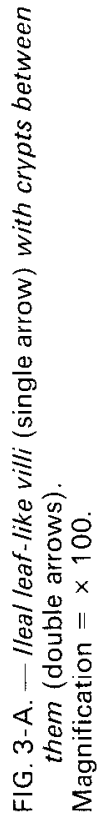


into the lumen by different mechanisms. Because of the thick mucin layer adhering strongly to epithelial and other surfaces of the duodenum, insignificant intestinal digestion and absorption takes place at this site. Mucin acts as a luminal barrier preventing intestinal enzymes from acting on feed nutrients in the duodenum. Further, permeability for most of the nutrient end-products may be reduced due to the mucin layer at the duodenum. Wall absorption of compounds is directly proportional to diffusion across the mucin layer, and is negatively correlated with the retention in the mucin (Nimmerfall and Rosenthaler, 1980). Studies on carbohydrate absorption in chickens, however, have yielded contrasting findings. In a study by Bogner et al. (1963), glucose absorption capacity was greatest in the mid-intestines, whereas Fearson and Bird (1968) found no differences between the segments when the in situ uptake of glucose was measured. More recently, Riesenfeld et al. (1980) found that absorption of glucose in chickens duodenum increased linearly as the dietary concentration increased from $39 \%$ to $73 \%$, suggesting that glucose absorption is concentration-dependent regardless of the mucin barrier.

As the digesta passes through the jejunum and the ileum, the actual « intestinal » digestion takes place through pancreatic and intestinal enzymes (Boorman, 1976 ; Levin, 1976 ; Freeman, 1976 ; Bondi, 1987).

As observed by SEM, the number of goblet cells in the jejunum and the ileum was small relative to that in the duodenum. Therefore, the minimal use of goblet mucin as a barrier at the distal part of the small intestines allows for better absorption. This is particularly so for the jejunum in spite of the larger number of goblet cells observed in this region relative to that in the ileum. The "paradox » here could, however, be explained by the findings of Mongin et al. (1976) in a study of absorption in chickens and rabbits in relation to the osmotic pressures along the digestive tract. As the digesta passed through duodenum, jejunum and ileum there was a change in the luminal osmotic pressure from 571 to 650 to 573 respectively. The higher osmotic pressure at the jejunum allowed for greater absorption due to a higher degree of polymer cleavage.

\section{Conclusions.}

The following are conclusions from this study and from relevant literature: 1. The abundance of villi observed at the duodenum makes this region serve mainly as a mixing site through an active villous motility resulting from nervous and hormonal stimulation.

2. Further, the large number of goblet cells on the duodenal villi makes duodenum act also as a neutralizing site through the action of goblet mucin, in addition to bile and pancreatic juices.

3. Because of the thick mucin layer adhering strongly to the duodenal epithelium, a small amount of absorption occurs in that region with the exception of carbohydrates.

4. In spite of the greater amount of goblet cells in the jejunum relative to that in ileum, jejunum is the main site of digestion and absorption of all nutrients. 
Differences in the absorptive capacity is due to the higher osmotic pressure in the jejunum.

Reçu en mars 1988.

Accepté en juillet 1988.

Acknowledgments. - I would like to express my sincere thanks and appreciation to Mr. $\mathrm{J}$. Krchma and all the staff of the Dept. of Entomology at Kansas State University for making the necessary facilities available, and for their valuable technical assistance.

Résumé. Observations, en microscopie électronique à balayage, des villosités intestinales et rapports éventuels avec les phénomènes de digestion et d'absorption chez les poulets.

La structure des villosités dans différentes parties de l'intestin grêle a été examinée en microscopie électronique à balayage chez des poulets de 22 semaines. Dans le duodénum, les villosités ont la forme de plaques avec un grand nombre de cellules en gobelet (cellules à mucus) réparties dans l'épithélium. Dans le jéjunum et dans l'iléon les villosités ont la forme de feuilles ; la quantité de cellules en gobelet est plus élevée dans le jéjunum que dans l'iléon, mais reste cependant inférieure à celle observée dans le duodénum.

L'effet éventuel des variations de structure des villosités et du nombre de cellules à mucus sur les processus de digestion et d'absorption est discuté.

\section{References}

BAYER R. C., CHAWAN C. B., BIRD F.H., MUSGRAVE S. D., 1975. Characteristics of the absorptive surface of the small intestines of chickens from 1 day to 14 weeks of age. Poult. Sci., 54, 155-169.

BOGNER P. H., HAINES T. A., McLAIN P. L., 1963. Comparison of aerobic and anaerobic active transport by different intestinal regions of young female chicks. Am. Zool., 3, 537.

BONDI A. A., 1987. Animal Nutrition (English Edition), John Wiley \& Sons, New York.

BOORMAN K. N., 1976. Digestion and absorption of protein, 27-61. In BOORMAN K. N., FREEMAN B. M., Digestion in the Fowl, British Poultry Sci. LTD.

CREAMER B., 1973. The small intestines, William Heinemann Medical Books LTD, London.

FEARSON J. R., BIRD F. H., 1968. Site and rate of active transport of D-glucose in the intestine of the fowl at various initial glucose concentration. Poult. Sci., 47, 1412-1416.

FORSTNER G. G., FORSTNER J. F., 1986. Structure and function of gastro-intestinal mucus, 125-143. In DESNUELLE P., SJOSTROM H., NOREN O., Molecular and cellular basis of digestion, Elsevier Sci. Publi. B.V. (Biomedical Division).

FREEMAN C. P., 1976. Digestion and absorption of fat, 117-142. In BOORMAN K. N., FREEMAN B. M., Digestion in the fowl, British Poultry Sci. LTD.

GREEN M., GREENE H. L., 1984. The role of the gastro-intestinal tract in nutrient delivery, Acad. Press, New York.

LEVIN R. J., 1976. Digestion and absorption of carbohydrates from embryo to adult, 63-116. In BOORMAN K. N., FREEMAN B. M., Digestion in the fowl, British Poultry Sci. LTD.

MONGIN P., LARBIER M., BOPTISTA N., LICOIS D., COUDERT P., 1976. A comparison of the osmotic pressures along the digestive tract of the domestic fowl and the rabbit. Br. Poult. Sci., 17. 379-382.

MORAN E. T., 1982. Small intestine-liver-pancreas complex: 1-Small intestine, 87-120. In MORAN E. T. Jr., Comparative nutrition of fowl and swine: The gastro-intestinal systems. Off. Educat. Practice, Univ. of Quelph. 
NIMMERFALL F., ROSENTHALER J., 1980. Significance of goblet cell mucin layer, the outermost luminal barrier to passage through the gut wall. Biochem. Biophys. Res. Comm., 94, 960-966.

RAO N. S., WILLIAM A. W., 1972. Normal and ischemic jejunal mucosa of mice scanning electron microscope study. J. Microscop., 15, 219-224.

RIESENFELD G., SKLAN D., BAR A., EISNER U., HURWITZ H., 1980. Glucose absorption and starch digestion in the intestine of the chicken. J. Nutr., 110,117-121.

WAXTER G. L., 1972. Lesions of transmissible gastroenteritis in the pig as determined by scanning electron microscopy. Am. J. vet. Res., 33, 1323-1328. 